\title{
Correspondence
}

\section{Safety glasses only for boys?}

SIR, We appreciate Tarkkanen and Tommila's reply' to our query $^{2}$ on their work. It appears that we did not, however, explain our intentions adequately.

Our concern is application of socioeconomic risk/benefit ratios in the prescription of glasses for safety reasons (we prescribe glasses with plastic lenses and plastic frames) for children and adults who have a permanent functional amblyopia in one eye. We agree with Tarkkanen and Tommila that this is a proper recommendation in principle because it protects the wearer from accidental trauma. And accidental trauma is the major single cause $(61 \%),{ }^{3}(45 \%)^{4}$ of loss of vision in the healthy eye in such patients.

On the other hand both adults and children and their parents innately and strongly resist the wearing of glasses even for this purpose. Peer pressure is a significant burden to the younger patient. Therefore we do not want to insist upon such safety glasses unless there is a real danger to the patient-i.e., a significant probability that such an accident may happen and cause the subject to be significantly visually handicapped per se. From the relatively greater risk of males to be traumatised it seemed possible that the probability of the loss of the better eye for a female patient in this situation might be so low that one would not be obliged to demand that they wear safety glasses.

Specifically, in Vereecken and Brabant's study ${ }^{4}$ of the 47 accidental traumatic loss cases $85 \%$ were male and $15 \%$ were female. (Our original query sought similar, additional data on this sex incidence.) Then from Tommila and Tarkkanen $^{3}$ we obtain an overall (trauma and disease) incidence of loss of the healthy eye of $1.75 / 1000$ (actually $1 \cdot 59 / 1000$ ) persons with permanent amblyopia in one eye.

Calculations then show that, if the cause is trauma in $47 \%$ (from combining the data from both studies, $(14+53)$ of $(23+119)=67$ of $142=47 \%)$ and the overall incidence of loss of the healthy eye is $1 \cdot 59 / 1000$, then the probability of loss from trauma is $47 \% \times 1 \cdot 59=0 \cdot 75 / 1000$. If the male to female ratio is $85 \% / 15 \%$, respectively, for males this incidence is $85 \% \times 0.75=0.635 / 1000$ and for females is $15 \% \times 0 \cdot 75=0 \cdot 112 / 1000$.

In other words, when we prescribe safety glasses for such patients we are protecting the males from a 1 in 1575 chance of losing their good eye from trauma and the females from a 1 in 8929 chance.

We should also include in these calculations the likelihood of improvement of vision in the amblyopic eye spontaneously or with pleoptic treatment after loss of the better eye. Vereecken and Brabant ${ }^{4}$ found $28 \cdot 5 \%$ improvement spontaneously or following pleoptic treatment. In fact $23 \%$ had a final visual acuity of $0.5(20 / 40)$ or better; $21 \%$, $0.6(20 / 32) ; 17 \%, 0.7(20 / 29)$ or better; and $7 \%, 0.8(20 / 25)$ or better.

We usually consider $0.5(20 / 40)$ not significantly handicapped because this vision in one eye qualifies for drivers licensing and almost all occupations. If we require one step better, $0.6(20 / 32)$, to ensure that the individual is not permanently visually handicapped, then the $20 \%$ possibility of such recovery further reduces the odds of becoming visually handicapped from trauma by $20 \%$. Prescribing safety glasses then protects males from an approximately a 1 in 1900 chance and females from a 1 in 10700 chance of becoming visually handicapped as a result of traumatic loss of their sole good eye.

Now since we cannot possibly protect everyone from everything, and even safety glasses do not protect the eye from trauma $100 \%$ of the time, what is our obligation in this regard?

One such benchmark in this regard was established several years ago when the principle of informed consent received so much attention. For complications which were not life threatening it was decided, admittedly quite arbitrarily, that if a complication occurred less frequently than 1:10000 it could be considered such a chance occurrence that the physician was not obliged to inform the patient about it. If it is not necessary even to warn, then it should not be necessary to demand against such a chance occurrence. And the incidence of loss in this situation in females exceeds $1: 10000$.

With regard to the economic cost/benefit ratio, a lifetime of wearing safety glasses is not an inconsiderable experience. If one purchases a new pair of glassses every five years for a reasonable cost of $\$ 50.00$ per pair, 10 pairs of glasses from age 5 to presbyopia at age 45 will cost $\$ 500$ per permanently amblyopic person. If only one in 10000 are saved the loss of their good eye by constant wearing of such glasses, then it will cost $\$ 500 \times 10000=\$ 5000000$ (5 million dollars) to save that one eye. Since such persons would probably not be totally blinded but only reduced to whatever vision they have in their permanently amblyopic eye, we may be talking about spending $\$ 5$ million to preserve only several lines on the eye chart for one patient.

In conclusion: there are three areas of consideration in recommending that persons with one permanently amblyopic eye wear safety type glasses to protect their remaining sound eye-namely (1) practical (patient acceptance), (2) social (as indicated by legal principles), and (3) economic. In all three areas there is significant support for a practice of not demanding safety glasses for females with one permanently amblyopic eye, rather for males only. Department of Ophthalmology,

PAUL E ROMANO University of Florida, College of Medicine,

Gainesville,

Florida 32610,

USA

\section{References}

1 Tarkkanen A, Tommila V. Safety glasses only for boys? $\mathrm{Br} \mathrm{J}$ Ophthalmol 1985; 69: 634.

2 Romano PE. Safety glasses only for boys? Br J Ophthalmol 1985; 69: 634.

3 Tommila V, Tarkkanen A. Incidence of loss of vision in the healthy eye in amblyopia. Br J Ophthalmol 1981; 85: 575-7.

4 Vereecken EP, Brabant P. Prognosis for vision in amblyopia after the loss of the good eye. Arch Ophthalmol 1984; 102: 220-4. 